\title{
Context effects on alcohol cognitions
}

Citation for published version (APA):

Krank, M., Wall, A., Stewart, S., Wiers, R. W. H. J., \& Goldman, M. (2005). Context effects on alcohol cognitions. Alcoholism-Clinical and Experimental Research, 29(2), 196-206.

https://doi.org/10.1097/01.ALC.0000153545.36787.C8

Document status and date:

Published: 01/01/2005

DOI:

10.1097/01.ALC.0000153545.36787.C8

Document Version:

Publisher's PDF, also known as Version of record

\section{Please check the document version of this publication:}

- A submitted manuscript is the version of the article upon submission and before peer-review. There can be important differences between the submitted version and the official published version of record.

People interested in the research are advised to contact the author for the final version of the publication, or visit the DOI to the publisher's website.

- The final author version and the galley proof are versions of the publication after peer review.

- The final published version features the final layout of the paper including the volume, issue and page numbers.

Link to publication

\footnotetext{
General rights rights.

- You may freely distribute the URL identifying the publication in the public portal. please follow below link for the End User Agreement:

www.umlib.nl/taverne-license

Take down policy

If you believe that this document breaches copyright please contact us at:

repository@maastrichtuniversity.nl

providing details and we will investigate your claim.
}

Copyright and moral rights for the publications made accessible in the public portal are retained by the authors and/or other copyright owners and it is a condition of accessing publications that users recognise and abide by the legal requirements associated with these

- Users may download and print one copy of any publication from the public portal for the purpose of private study or research.

- You may not further distribute the material or use it for any profit-making activity or commercial gain

If the publication is distributed under the terms of Article $25 \mathrm{fa}$ of the Dutch Copyright Act, indicated by the "Taverne" license above, 


\title{
Context Effects on Alcohol Cognitions
}

\author{
Marvin Krank, Anne-Marie Wall, Sherry H. Stewart, Reinout W. Wiers, and Mark S. Goldman
}

\begin{abstract}
This article summarizes a symposium on context and alcohol-related cognitions presented at the 2004 Annual Meeting of the Research Society on Alcoholism in Vancouver, British Columbia, Canada. The studies reported here examine how the manipulation of contextual variables influences the availability of alcohol outcome expectancies and implicit memories for alcohol associations. The symposium illustrates the range of context variables and shows some of the potential impact of retrieval on cognitions that predict alcohol use. Two of the studies explore naturalistic drinking contexts: one examines the impact of stress induction, and one assesses within survey question placement effects. A variety of measures of alcohol cognitions were used. The results demonstrate that alcohol cognitions are more accessible in alcoholrelated contexts. Moreover, availability of alcohol associations and expectancies depended on individual differences. These results underscore the potential value of memory processes in the retrieval and measurement of alcohol cognitions. The findings have direct implications for improving methods of predicting alcohol use and in understanding the role of alcohol cognitions in various contexts associated with alcohol use.
\end{abstract}

Key Words: Alcohol Cognition, Individual Differences, Outcome Expectancies, Implicit Memory, Prediction, Context Effects, Retrieval.

$\mathbf{M}^{2}$ UCH RESEARCH HAS demonstrated that alcohol expectancies and associations are important correlates of patterns of alcohol use and abuse (e.g., Goldman et al., 1999; Stacy, 1997). Both explicit and implicit measures of these alcohol cognitions prospectively predict transitions in alcohol use and may be important targets for change in prevention and intervention programs (Darkes and Goldman, 1993; Wiers et al,, 2002a). The present symposium explores the role of context in the accessibility of cognitions that are relevant to alcohol use. As cognitive representations, principals of encoding specificity (Tulving, 1983) should govern retrieval of alcohol expectancies and associations in contexts associated previously with drinking. Thus, accessibility of alcohol cognitions should be responsive to alcohol-related context manipulations.

Department of Psychology (MK), Okanagan University College, Kelowna, British Columbia, Canada; Department of Psychology (A-MW), York University, Toronto, Ontario, Canada; Department of Psychology (SHS), Dalhousie University, Halifax, Nova Scotia, Canada; Department of Experimen. tal Psychology (RW), University of Maasiricht, Maastricht, The Netherlands; and Department of Psychology (MSG), University of South Florida, Tampa, Florida

Received for publication September 30, 2004; accepted October 26, 2004. This study was funded by the Social Science and Humanities Research Council of Canada and Canadian Institutes of Health Research (MK, SHS), the Alcoholic Beverage Medical Research Foundation (A-MW), and the Netherlands Organisation for Scientific Research Vidi-Grant 452.02.005 (RWW).

Reprint requests: Marvin Krank, PhD, Okanagan University College, Department of Psychology, 3333 University Way, Kelowna, BC VIV IV7, Canada; Fax: 250-470-6009; e-Mail:mkrank@ouc.bc.ca.

Copyright (C) 2005 by the Research Society on Alcoholism.

DOI: 10.1097/01.ALC.0000153545.36787.C8
Four different approaches to context effects were presented in the symposium. The first study by Wall and associates describes how a naturalistic context associated with alcohol use, a campus bar, enhances the accessibility of alcohol outcome expectancies among light-, moderate-, and heavy-drinking college students. The second set of studies by Stewart and colleagues consists of four experiments on the effect of inducing emotional states on alcohol expectancies and implicit cognitions held by individuals with differing reasons for drinking. Mood inductions modified explicit and implicit cognitions about alcohol differentially in drinkers with different drinking motivations. The third set of studies by Wiers and collaborators presents data on cognitive and environmental manipulations of alcohol context and their effect on both implicit and explicit associations. Two studies compared the effects of a cognitive cue and a naturalistic bar setting on the accessibility of alcoholrelated memories and craving. The final study by Krank and associates examines how asking questions about alcohol use increases the subsequent level and improves the predictive value of alcohol-related implicit memory responses in youths. Goldman's discussion places the series of studies described here in the larger context of alcohol cognition in a transdisciplinary approach to alcohol use.

The effects of context on alcohol cognitions are important for several reasons. First, these studies describe important variables that influence the dynamic cognitive processes that control accessibility of alcohol expectancies and associations. Accessibility determines when and how alcohol cognitions are remembered and, thus, are more likely to influence alcohol use behaviors. Second, to the extent that better retrieval conditions, such as those provided by con- 
text manipulations, improve the measurement of alcoholrelevant underlying cognitions, they may also improve the predictive value of measures of alcohol cognitions. Given that changes in these cognitions may predate transitions to alcohol use (Krank et al., 2003; Stacy, 1997), their effective measurement will be an important tool in the development of effective prevention and intervention.

\section{ALCOHOL OUTCOME EXPECTANCIES, MEMORY} ACCESSIBILTY, AND SITUATIONAL VARIATION IN COLLEGE STUDENTS' DRINKING BEHAVIOR

\section{Anne-Marie Wall, Sherry McKee, and Riley Hinson}

Originating with research using the balanced placebo design (Marlatt et al., 1973), it has become increasingly apparent that individuals' beliefs about alcohol's effects [alcohol outcome expectancies (AOEs)], particularly of a positive nature, are important predictors of general drinking patterns (for a review, see Goldman et al., 1999). Contemporary models conceptualize AOEs as learned associations that are stored in memory. Evidence is accumulating that the endorsement of AOEs and the ease with which they are accessed from memory are independent predictors of consumption patterns (e.g., Stacy, 1997; Wiers et al., 2003a,b).

It is well established, however, that drinking patterns vary across environmental contexts such that individuals consume alcohol more often at home, but consumption levels are higher in bar settings (Glicksman et al., 2000; Single and Wortley, 1993). Similar findings have been reported in experimental studies involving exposure to naturalistic bar settings (Wigmore and Hinson, 1991). Theoretically, to the extent that AOEs mediate drinking behavior, they should similarly vary across environmental contexts. Specifically, according to the principle of encoding specificity (Tulving, 1983) and the situational-specificity hypothesis, the endorsement and accessibility of AOEs from memory should be facilitated in contexts associated previously with drinking behavior as such contexts would serve as implicit primes. It has been demonstrated that AOEs vary across vignettes (Levine and Goldman, 1989; MacLatchyGaudet and Stewart, 2001), and our previous work has supported the notion that exposure to naturalistic bar settings influences the endorsement and valence of AOEs (Wall et al., 2000), as well as the ease with which AOEs are accessed from memory (Wall et al., 2001). In this talk, the authors presented findings from a study that was designed to address whether environmental context influences both the accessibility of AOEs from memory and alcohol consumption. To date, these empirical questions have not been examined concurrently within a single investigation. As positive, as opposed to negative, AOEs are thought to be critical predictors of drinking behavior, only the accessibility of positive expectancies was examined. In this study, the potential moderating effects of sex and drinking status (high versus low, based on a median split of total monthly consumption) were also explored.
Using a separate experiment paradigm (Roehrich and Goldman, 1995; Stein et al., 2000), 212 (102 women) college student drinkers participated. Initially, individuals were invited to participate in a "lifestyle study" in which they completed a large questionnaire battery that assessed a variety of addictive behaviors (drug and alcohol use, gambling, etc.), exercise, personality attributes, medical and psychiatric history, and clinically significant levels of drug and alcohol use. After completing the questionnaire, participants were invited to participate in a "second," ostensibly unrelated experiment that would extend our research program on lifestyle behaviors. Responses of interested individuals were examined subsequently to determine their eligibility. Individuals were included in the "second" study when they were of legal drinking age (19 in Ontario) and had consumed alcohol in the previous 30 days. Potential participants were excluded when (1) their alcohol and drug use fell within the clinically significant range, (2) there were any medical or psychiatric contraindications, and (3) women were pregnant or attempting to become pregnant. Individual testing sessions were scheduled approximately 2 weeks later.

Upon arrival for the "second" experiment, participants were informed that they would be randomly assigned to one of six conditions that tapped specific lifestyle behaviors, including alcohol. So as to minimize demand characteristics, each participant rolled a die ostensibly to determine to which condition which he or she would be assigned. All participants were informed, however, that they had been assigned to the alcohol condition. Within sex, participants were randomly assigned to one of two environmental contexts: a laboratory setting or an on-campus bar. Individuals were not informed of the context manipulation but rather were instructed that they would be participating in a consumer preference study involving alcohol. Each participant then was escorted to his or her randomly determined environmental context. Drawing on methods used in the attitude literature (Fazio, 1990) and consistent with recent memory-based expectancy research (Palfai et al., 2000; Wall et al., 2001), accessibility of AOEs was assessed using reaction-time measures. Specifically, once in their designated context, participants were required to respond to practice items and the Comprehensive Effects of Alcohol (Fromme et al., 1993) scale on a laptop computer. After this, a modified taste-rating task (Marlatt et al., 1973), comparable to those used previously in the literature (Palfai et al., 2000; Roehrich and Goldman, 1995; Stein et al., 2000), was used.

Independent of whether individuals drank in the oncampus bar or the laboratory, the amount of alcohol consumed varied as a function of context, sex, and drinking status. Heavy drinkers and men consumed more alcohol, The effect of drinking status was qualified as a function of context and sex. Specifically, heavy-drinking women, as opposed to their light-drinking counterparts, consumed significantly more alcohol in the on-campus bar. For male 
college students, context did not interact with the amount of alcohol consumed. Comparable analyses conducted on accessibility of positive AOEs yielded a similar pattern of results, with heavy-drinking women demonstrating lower reaction times in the on-campus bar setting. When the impact of environmental context, sex, and drinking status on the accessibility of specific positive AOEs (enhanced sociability, liquid courage, enhanced sexuality, and tension reduction) was examined, a number of effects were found. Specifically, expectations regarding alcohol-related enhanced sociability were more readily accessed by women and heavy drinkers. Heavy, in comparison with light, drinkers also more readily accessed expectations concerning alcohol-related "liquid courage." Paralleling the findings observed with the accessibility of total positive AOEs, heavy-, in comparison with light-, drinking women accessed expectations regarding alcohol-related enhanced sexuality and tension reduction more rapidly in the on-campus bar setting.

In summary, these findings suggest that environmental context influences drinking behavior and the accessibility of specific AOEs, but its effect is moderated by sex and drinking status. Overall, results suggest that heavy-drinking female college students may be particularly at risk for excessive consumption and alcohol-related, negative sexual consequences in bar settings. Interventions that challenge AOEs may be improved by incorporating exposure techniques that target sex-specific beliefs about alcohol across drinking groups.

\section{EMOTIONAL CONTEXT EFFECTS ON ALCOHOL COGNITIONS IN ENHANCEMENT- AND COPING- MOTIVATED DRINKERS}

\section{Sherry H. Stewart and Cheryl D. Birch}

For decades, researchers have sought to understand the mood triggers for drinking behavior, but research on the effects of mood on drinking has produced highly inconsistent results. Mood-based theories of problematic alcohol consumption have been criticized for their failure to take into account important individual difference variables (e.g., Greeley and Oei, 1999). One potentially important individual difference in moderating the effects of mood on drinking behavior is "drinking motives," or reasons for drinking. Motivational models of drinking (e.g., Cooper, 1994) recognize that people drink for a variety of different reasons and in a variety of different contexts. Cooper's (1994) model distinguishes between coping motives (CM; drinking to reduce or avoid an unpleasant emotional state) and enhancement motives (EM; drinking to increase a desirable emotional statc). Both of these internal motives have been shown to be associated with heavy and problem drinking (Cooper, 1994). Previous work (Carrigan et al., 1998) has shown that $\mathrm{CM}$ drinkers report drinking in response to unpleasant emotions, whereas EM drinkers report drinking in response to pleasant emotions. These self-report results required experimental verification. Moreover, emotional context may influence drinking behavior via effects on explicit and/or implicit alcohol cognitions, and these effects, too, may be moderated by drinking motives (see review by Birch et al., in press).

In this talk, the authors reported on the result of a series of four experiments that examined the effects of emotional context on aspects of alcohol cognition in CM and EM drinkers. In each study, participants were university drinkers who were selected on the basis of extreme scores on the CM or EM subscale of Cooper's (1994) Revised Drinking Motives Questionnaire. Experiment 1 (Stewart et al., 2002) investigated whether $24 \mathrm{CM}$ and $24 \mathrm{EM}$ drinkers differed in degree of activation of alcohol concepts after exposure to negative affect primes (e.g., rejected), positive affect primes (e.g., confident), and neutral primes (e.g., playroom). The primed Stroop task (Segal et al., 1995) was used as the measure of implicit alcohol-related cognition. Implicit alcohol cognitions were considered activated when participants had longer color-naming latencies for alcohol targets (e.g., beer) versus nonalcohol targets (e.g., coat). As expected, positive (but not negative) affect primes activated alcohol schema for EM drinkers, and negative affect (but not neutral) primes activated alcohol schema for CM drinkers. Unexpected, however, neutral primes also activated alcohol schema for EM drinkers, and positive affect primes also activated alcohol schema for CM drinkers. Thus, the results were partially consistent with the mood-specific priming hypothesis. The next three experiments examined the effects of actual mood induction on various aspects of explicit and implicit alcohol-related cognition in CM and EM drinkers. Target negative or positive moods were induced through the use of musical mood induction procedures (MMIP); in each case, target moods were successfully induced.

Experiment 2 (Birch et al., 2004) investigated whether mood induction via MMIP differentially increased the strength of specific explicit alcohol cognitions (i.e., alcohol outcome expectancies) for CM versus EM drinkers. Explicit expectancies were measured by two relevant subscales of Singleton et al.'s (1994) state expectancies measure: Reward Expectancies (e.g., "Drinking would make things seem just perfect") and Relief Expectancies (e.g., "If I used alcohol right now, I would feel less tense"). Forty-four CM and 42 EM drinkers were randomly assigned to a positive or a negative MMIP. State expectancy scores were obtained before and after mood induction. As hypothesized, only CM drinkers in the negative mood condition reported increased relief expectancies, and only EM drinkers in the positive mood condition reported increased reward expectancies, after mood induction. It remained to be determined whether mood induction would have similar effects on implicit alcohol cognitions.

Experiment 3 (see Birch et al., in press) (Study 1) investigated whether $\mathrm{CM}$ and $\mathrm{EM}$ drinkers differ in their activation of implicit alcohol cognition on a modified Stroop 
task after mood induction. Participants were $44 \mathrm{CM}$ and 42 EM drinkers who were randomly assigned to the negative or positive MMIP condition. After mood induction, participants completed a Stroop color-naming task involving a series of alcohol (e.g., beer) or control (e.g., coat) target words. Selective processing of alcohol cues was inferred when participants showed delayed latencies in colornaming alcohol versus control targets. As expected, EM drinkers in the positive (but not negative) mood condition showed selective processing of alcohol targets. However, unexpected, $\mathrm{CM}$ drinkers in the negative mood condition failed to show selective processing of alcohol targets. Thus, findings were similar to results from experiments 1 and 2 for the EM drinkers but not for the CM drinkers. Differences from experiment 1 findings might be due to different effects of verbal affect versus mood induction triggers. Differences from experiment 2 results might be due to different mood induction effects for explicit versus implicit cognition. However, an additional difference was that experiment 2 examined mood activation of specific alcohol outcome expectancies (reward versus relief), whereas experiment 3 did not. Thus, experiment 4 focused on the mood activation of implicit cognitions regarding reward and relief alcohol outcomes in CM and EM drinkers.

Experiment 4 (Birch et al., 2004b) (Study 2) investigated whether CM and EM drinkers differ in their implicit associations in memory between alcohol and specific outcomes on the Extrinsic Affective Simon Task (EAST) (de Houwer, 2003) as a function of mood induction. Eighty participants (CM or EM drinkers) were randomly assigned to either a positive or a negative MMIP. Participants completed the EAST after mood induction. On the EAST, participants were asked to categorize a series of words. Target words, pertaining to either alcohol (e.g., beer) or non-alcohol (e.g., soda) appeared in one of two colors. Participants were asked to press one key ("P" or "Q") if the word was blue and the other key if the word was green. The other set of words were attributes and appeared in white. Participants were asked to categorize these by pressing one of two response keys (again, "P" or " $Q$ ") according to whether they pertained to relief (e.g., comfort, relaxed) or reward (e.g., cxcited, delight) outcomes. The rationale behind this task is that when the same response is required for two concepts that are strongly associated in memory, response times will be faster, whereas when the same response is required for two concepts that are weakly associated (or dissociated) in memory, response times will be slower. We expected that only EM drinkers in the positive MMIP would have fast alcohol-reward (versus alcoholrelief) associations and that only $\mathrm{CM}$ drinkers in the negative MMIP would have fast alcohol-relief (versus alcoholreward) associations. Results showed that, as expected, EM drinkers associated alcohol with reward outcomes after positive (but not negative) mood induction. However, unexpected, $\mathrm{CM}$ drinkers failed to show evidence of implicit associations between alcohol and relief outcomes after negative mood induction.

In sum, the findings suggest that there may be some differences in mood activation effects when one uses verbal affect cues as opposed to actual mood induction procedures. Across the three studies using MMIPs, positive mood activated explicit and implicit cognitions about alcohol and reward drinking outcomes in EM drinkers. However, the findings were less consistent for negative mood activation of alcohol cognition in CM drinkers. Although negative mood may activate explicit relief expectancies in $\mathrm{CM}$ drinkers, it does not seem to have similar activating effects on implicit alcohol-related cognitions in this group. Reasons for the failure to observe negative mood induction of implicit alcohol cognition in $\mathrm{CM}$ drinkers were discussed, and implications of the findings for improving interventions for these two types of drinkers were reviewed.

\section{CONTEXT EFFECTS ON IMPLICIT AND EXPLICIT ALCOHOL-RELATED COGNITIONS}

\section{Reinout W. Wiers, Jeroen Granzier, and Remco C. Havermans}

In this presentation, we briefly describe two experiments that investigated context effects on implicit alcohol-related cognitions. Both concepts need some introduction. Context can refer to different things: to different physical situations (here a bar laboratory versus a neutral laboratory), to alcohol-related cues (e.g., a cue-exposure paradigm), or to assessment context [e.g., the order of questions may influence the scores (see Schwartz, 1999)]. Implicit and explicit cognitions may refer to different things as well: to different assessment strategies, with implicit strategies being more automatic and indirect (e.g., an attitude is derived from a difference in two reaction times), whereas explicit assessment strategies more rely on introspection and are more open to conscious control [e.g., a questionnaire (De Houwer, 2003; Fazio and Olson, 2003)]. Some investigators have argued that implicit measures also tap into different underlying processes, given their unique predictive properties above explicit measures (e.g., Stacy, 1997; Wiers et al., 2002b). Furthermore, neurobiological research indicates that neural circuits that are important in addiction are not open to introspection (e.g., Robinson and Berridge, 2003; White, 1996). In social cognition research, recent evidence suggests that implicit and explicit cognitions have different representational formats [implicit: dynamic associations; explicit: more stable if-then statements (Strack and Deutsch, 2004)], and in line with this idea, it has been found that implicit cognitions are more sensitive to context effects than explicit cognitions (Blair, 2002). Here we assessed the influence of different context manipulations on implicit alcohol-related cognitions.

In a first study (Havermans et al., 2005), we tested 70 undergraduates ( 57 women) either in a bar laboratory or in a neutral laboratory (between-subjects). Participants were 
told that the main purpose of the experiment was creative writing. They performed two sentence-generation tasks that started with either the word "milk" or the word "beer" (within-subjects, in balanced order). This served as a manipulation of assessment-context (the first word served as a prime). These tasks were based on a sentence-generation task (Glautier and Spencer, 1999). Both tasks consisted of 15 words (after the first, which was either milk or beer): 4 alcohol-ambiguous words and 10 fillers. Dependent variable was the number of alcohol-related sentences. A verbal prime ("milk" versus "beer") $\times$ context (bar versus office) ANCOVA was conducted with regular alcohol use as covariate. The covariate was significant $[F(1,67)=4.68, p<$ 0.05 ], with alcohol consumption predicting the number of alcohol-related sentences. A main effect was found for situational context $[F(1,67)=7.56, p<0.01]$ but not for the word prime $(F<1)$. There was an interaction between prime and context $[F(1,67)=4.17, p<0.05]$. Follow-up tests indicated that for the participants in the bar, the prime word did not affect the interpretation of the alcoholambiguous words, whereas the word "beer" did promote an alcohol-related interpretation of the ambiguous words in participants who were tested in the office $(t=2.17, p<$ 0.05 ). This result demonstrates that the two context manipulations were not additive and that the effect of the prime was more pronounced in the neutral context [which could be due to a ceiling effect in the bar (see Havermans et al., 2005)].

The second experiment consisted of two related studies. In the first (Wiers et al., 2003a), undergraduate students ( $n$ $=119$ ) were tested using different implicit and explicit tests of alcohol-related cognitions. They performed two IATs (Implicit Activation Tests), one assessing valence and one arousal associations with alcohol as compared with soda (as in Wiers et al., 2002b) and tests of explicit expectancies using the same words. In addition, they performed two versions of the EAST (De Houwer, 2003), another reaction time test of associations that has the advantage that the associations are not relative for the target category (alcohol versus soda). With the two versions, the same emotional dimensions were assessed (valence and arousal). A third implicit test consisted of first associations to alcoholambiguous words (Stacy, 1997). Main results of the first phase of this experiment was a replication of earlier alcohol IAT effects (De Houwer et al., 2004; Wiers et al., 2002a,b): heavy drinkers showed negative and arousal associations with alcohol as compared with soda. Results on the EAST were inconsistent for valence but confirmed the implicit alcohol-arousal associations. In the second phase of the experiment (Wiers et al., unpublished data), a representative subgroup ( $n=54$ ) was tested in a cue-reactivity experiment that took place 6 weeks later, either in a neutral office or in the bar laboratory (combining the first and second types of context manipulation). Participants first held and then sipped water (baseline), followed by two similar trials with their favorite drink. In addition, they performed a subset of the implicit and explicit tests of the first test phase. A context (bar versus office) $\times \operatorname{sex} \times$ drinker (light, heavy) $\times$ time (baseline, alcohol-cue-1, alcohol-cue-2) mixed ANOVA was conducted with the subjective craving scores (DAQ, Desire for Alcohol Questionnaire) as dependent variable. There was a significant $\operatorname{sex} x$ context $\times$ time interaction $[F(2,92)=3.55, p<0.05]$. Follow-up tests indicated that men were more reactive to the cue-exposure manipulation (i.e., greater increase in craving scores) in the neutral laboratory than in the bar ( $p$ $<0.05)$, with no significant difference in women $(p>0.20)$. Similarly, for the number of alcohol-related associations, a significant sex $\times$ context effect was found $[F(1,49)=6.48$, $p<0.05]$. Follow-up tests indicated that men produced significantly more alcohol-related associations in the neutral context than in the bar laboratory $(p<0.05)$, with no significant difference in women $(p>0.20)$. On explicit expectancies, no context effects were found for positive, negative, and sedation expectancies. However, explicit arousal expectancies were significantly stronger in the bar context than in the neutral context, as compared with the first assessment $(p<0.05)$. Finally, in a hierarchical regression analysis, we tested which variables predicted individual differences in cue-induced craving. Of the background variables, sex and context were not significant predictors (and were removed from the equation), whereas habitual drinking did significantly predict cue-induced craving ( $8 \%$ variance explained). In a second step, we introduced the variables assessed during the second session, and the only significant predictor was the number of ambiguous words associated with alcohol (adding 15\% to the variance explained in craving). In the final step, we tested variables that were assessed 6 weeks earlier, and the IAT and EAST arousal associations predicted extra variance in cueinduced craving ( 6 weeks later) at borderline significance ( $p$ $=0.06$; adding $9 \%$ to the variance explained).

Taken together, these experiments underscore that different context manipulations need to be distinguished (the ones tested here were situational, drug cues and withinassessment cues) and that they cannot simply be added up. To the contrary, both experiments demonstrated that the effect of a second contextual cue can be smaller in a situation in which the first cue is already alcohol related: in the first study, the alcohol word prime produced priming only in the neutral office and not in the bar, and in the second experiment, the effect of the alcohol cue on craving and on alcohol-related associations to ambiguous words was larger in the office than in the bar (in men). One possible explanation of the latter results could be related to context effects in sensitization found in animal work (Crombag and Robinson, 2004): sensitization is stronger in a novel than in a familiar environment. Men drink more and more often in bars; therefore, the alcohol stimulus could evoke a stronger sensitized response in a neutral environment for them. Second, the results in the second study add to the evidence that implicit measures of alcohol-related cognitions assess 
something else than explicit measures and may be more closely related to the dynamic context-sensitive processes involved in craving than explicit measures (cf. Palfai and Ostafin, 2003; Wiers et al., 2002b).

\section{EFFECTS OF ALCOHOL CONTEXT ON MEASURES OF IMPLICIT ASSOCIATIONS AND THEIR PREDICTIVE VALUE IN YOUTH}

\section{Marvin Krank and Tricia Johnson}

Cognitive associations between drinking and its context and related outcomes can be assessed without awareness using implicit memory tasks. Such implicit alcohol associations correlate strongly with drinking behavior and predict transitions in alcohol use prospectively in adolescents (Krank et al., 2003; Stacy, 1997). The study presented here addressed how context manipulations that may inadvertently occur in standard assessment techniques such as placement in survey influence the retrieval of implicit memory associations. Much work indicates that retrieval manipulations are critical determinants of survey responses (Banaji et al., 1996; Schwarz, 1999)

The present study was imbedded in a longitudinal survey study of adolescent risk-taking behaviors. The Project on Adolescent Trajectories and Health has followed 1303 grade 7,8 , and 9 students for 3 years beginning in the spring of 2002. The students from a single school district in central British Columbia, Canada, were surveyed on a wide range of activities (including violence, drug use, alcohol use, sports, hobbies, dating, dating partners, media exposure, etc.), social factors (e.g., family history), health outcomes, and personality factors. Cognitive measures of outcome expectancies and implicit associations with drugs and alcohol were obtained during the survey session. The data reported here are based on results from the first and second years of the Project on Adolescent Trajectories and Health study. Eighty-seven percent (1142) of the participants completed both the first- and the second-year surveys (627 were female and 515 were male; 401, 411, and 330 were from grades 8,9 , and 10 , respectively).

The present study was designed to test whether conditions designed to enhance implicit memory associations influence their predictive value. We predicted that context manipulations would selectively enhance retrieval (accessibility) of alcohol associations in individuals with preexisting associations. This prediction differs from the alternative view that an alcohol context might simply increase the base rate of alcohol-related responses. Such an outcome would be nonspecific and increase the overall level of noise in the implicit measure. Increasing the noise should interfere with the predictive value of the implicit measures. By contrast, a context retrieval effect would selectively increase alcohol responses in individuals with preexisting memory associations. To the extent that these underlying memory associations predict future alcohol use (Krank et al., 2003; Stacy, 1997), the retrieval-based increase in alcohol responses would provide a better predictive measure; the greater accessibility of these associations should more accurately predict current and future alcohol use.

The context of implicit memory tasks was manipulated by changing the location of the task in the survey in the first year of the longitudinal study. A neutral context was provided by placing the implicit task at the beginning of the survey before any questions about drugs or alcohol. The context was neutral because the survey was presented as containing a number of lifestyle questions. An alcohol context was generated by placing the implicit task either directly after questions about alcohol use (immediate) or later in the survey (delayed). The delay condition was introduced to determine whether the context effect was time limited or persistent.

Implicit cognitions were measured by either an ambiguous word association task or a behavioral associates task (Stacy, 1997). In the ambiguous word or homograph task, open-ended responses were elicited by potential alcohol associates with alternative nonalcohol meanings such as draft or mug. In the behavioral associate's task, the participants were asked to write down the first activity that came to mind in response to an outcome such as having fun or feeling relaxed. In both measures, the number of alcohol responses was coded by two raters who were unaware of the experimental condition and the other responses of the participants. The $\mathrm{ks}$ calculated for each target word or phrase were generally high ( 0.9 or greater) and exceeded 0.8 in all cases. The mean of the sum alcohol score for each rater was used in this analysis.

The order of implicit memory tasks was counterbalanced for position within the survey. This counterbalancing comprised the context manipulation for the present study. For each participant, the behavioral associates task was presented at the beginning of the session (prealcohol), immediately after questions about alcohol use (postalcohol immediate), or several sections later (postalcohol delayed). The homograph measure was also presented in one of these contexts. If the behavioral associate was presented in the prealcohol condition, then the homograph task was presented in either the immediate or the delayed condition. Another picture drawing task (not analyzed here) was presented in the remaining condition. Counterbalancing resulted in six different survey versions. All participants randomly received one of the six versions of a survey in small groups.

The level of alcohol use varied as a function of grade, with $30 \%$ of grade 7 students having had one or more drinks in the past year. This percentage increased to nearly $70 \%$ by the second year in grade 10 students. A small but significant percentage of grade 10 students $(\sim 20 \%)$ reported being drunk within the past week in the second year of the survey. Self-reported drunkenness is highly correlated with marijuana use and other problem behaviors (Johnson et al., 2004). Given the age range of the sample in the first year (12-15), approximately half $(47.6 \%)$ of the 
Table 1. Regression Coefficients That Predict Drinking Behavior in Year 1 as a Function of Implicit Memory Measures Controlling for Grade and Sex

\begin{tabular}{|c|c|c|c|c|}
\hline \multirow[b]{3}{*}{ Position in survey } & \multicolumn{4}{|c|}{ Alcohol measure } \\
\hline & \multicolumn{2}{|c|}{ Days drank in past 30} & \multicolumn{2}{|c|}{ Usual no. of drinks } \\
\hline & $\begin{array}{r}\text { Behavior } \\
\text { associates }\end{array}$ & Homographs & $\begin{array}{r}\text { Behavior } \\
\text { associates }\end{array}$ & Homographs \\
\hline Prealcohol & 0.284 & 0.210 & 0.243 & 0.198 \\
\hline Postalcohol immediate & $0.387^{\mathrm{a}}$ & $0.288^{a}$ & $0.409^{a}$ & $0.396^{\mathrm{a}}$ \\
\hline Postalcohol delayed & $0.313^{\mathrm{a}}$ & $0.268^{a}$ & $0.432^{\mathrm{a}}$ & $0.313^{\mathrm{a}}$ \\
\hline
\end{tabular}

Regression coefficients for each individual model all were significant at $p<0.001$.

" Indicates significant $(p<0.05)$ difference from the regression coefficient in the prealcohol condition.

sample had not had one or more standard drinks (labeled nondrinkers). This dichotomy allows an interesting comparison between nondrinkers and drinkers in year 1 and is used in the analysis presented below.

The first test of retrieval effects was whether the position in the survey modified the behavioral associate or homograph score. The location changed the behavioral associates' score but only in drinkers who had at least one or more drinks previously $[F(2,661)=6.09, p<0.05]$. Postalcohol immediate had higher score than the other two conditions (prealcohol: mean $=0.12, \mathrm{SEM}=0.03$; postalcohol immediate: mean $=0.27, \mathrm{SEM}=0.06$; and postalcohol delayed: mean $=0.17, \mathrm{SEM}=0.04)$. No differences were evident in nondrinkers because no alcohol-related behavioral associates were produced by this group. Homograph probes produced measurable levels of alcoholrelated responses in both Drinkers (mean $=1.10, \mathrm{SEM}=$ 0.049 ) and nondrinkers (mean $=0.66, \mathrm{SEM}=0.038$ ). Homograph scores were influenced by the survey position in both drinkers $[F(2,662)=8.18, p<0.05]$ and nondrinkers $[F(2,599)=11.47, p<0.02]$. The pattern of response showed that postalcohol scores were higher than prealcohol scores. The pattern was similar in nondrinkers (prealcohol: mean $=0.36, \mathrm{SEM}=0.067$; postalcohol immediate: mean $=0.84, \mathrm{SEM}=0.066$; and postalcohol delayed, mean $=$ $0.77, \mathrm{SEM}=0.062$ ) and drinkers (prealcohol: mean $=0.94$, $\mathrm{SEM}=0.082 ;$ postalcohol immediate: mean $=0.1 .22, \mathrm{SEM}$ $=0.083$; and postalcohol delayed: mean $=1.18, \mathrm{SEM}=$ 0.086 ).

Given the variability introduced by the survey position, we next asked whether the prediction of drinking behavior changed as a function of the independent variable. The regression analyses reported here are simplified versions testing each cognitive measure, behavioral associates score and the homograph score, controlling for sex and grade separately against two measures of drinking behavior: number of days drinking in the past month and the usual number of drinks. The purpose of these analyses is to show the effect of the retrieval manipulation on the predictive value of each of these measures independently. More detailed analysis of the predictive value of cognitive measures is reported elsewhere (Ktank et al., 2003). Table 1 reports the separate regressions on both drinking measures as a function of survey position. For both measures and both predictor variables, the regression provided a significant model and the regression coefficient improved significantly in the postalcohol conditions. Alcohol context improved the regression coefficient for the implicit measure as a predictor of current drinking behavior.

These implicit measures, taken from the first year of the study, continued to predict drinking behavior in the second year, including the initiation of drinking in youths who did not drink in year 1. The regressions controlled for sex and grade and were split according to drinking status in year 1 (nondrinkers and drinkers, defined above). The drinking measures examined included the number of days drinking in the past 30 days, usual number of drinks, recency of last drinking episode, and recency of last time drunk. Behavior associates predicted future drinking on all measures in drinkers [all $\beta>0.121, t(1,577)>2.92, p<0.005$ ]. Nondrinkers did not produce any behavioral associates in year 1 , so this measure could not be used for regression in this subgroup. Homograph scores, however, were significant predictors of drinking measures in year 2 for all measures in drinkers [all $\beta>0.261, t(1,577)>6.27$, all $p$ $<0.001]$ and in nondrinkers [all $\beta>0.171 t(1,577)>3.42$, all $p<0.001]$.

Table 2 shows further separate regression analyses using behavior associates and homographs against a number of drinking measures taken in year 2 . These regressions control for sex and grade and are shown as a function of the position in the survey. For behavior associates, seven of eight possible comparisons revealed significantly higher model regressions on scores with an alcohol context (postalcohol immediate and postalcohol delayed) than those without an alcohol context (prealcohol). For homographs, only two of eight possible comparisons revealed significantly higher model regressions. Both of these were on scores that were taken immediately after the alcohol questions (postalcohol immediate). The prospective predictive value of implicit associations was improved by the alcohol context manipulation at least in some conditions. There is some suggestion in both the mean increases and the pattern of improvement that the immediate postalcohol context was more effective than the delayed condition, but this observations and the relationship to particular drinking measures requires further investigation.

The results of the present study confirm the concurrent and prospective predictive value of implicit memory measures in relationship to adolescent drinking. They also indicate that for one of the two measures, homograph association, these measures predict the initiation of drinking in 
Table 2. Prediction of Measures of Alcohol Consumption in Year 2 as a Function of Implicit Memory Measures in Year 1 Controlling for Grade and Sex

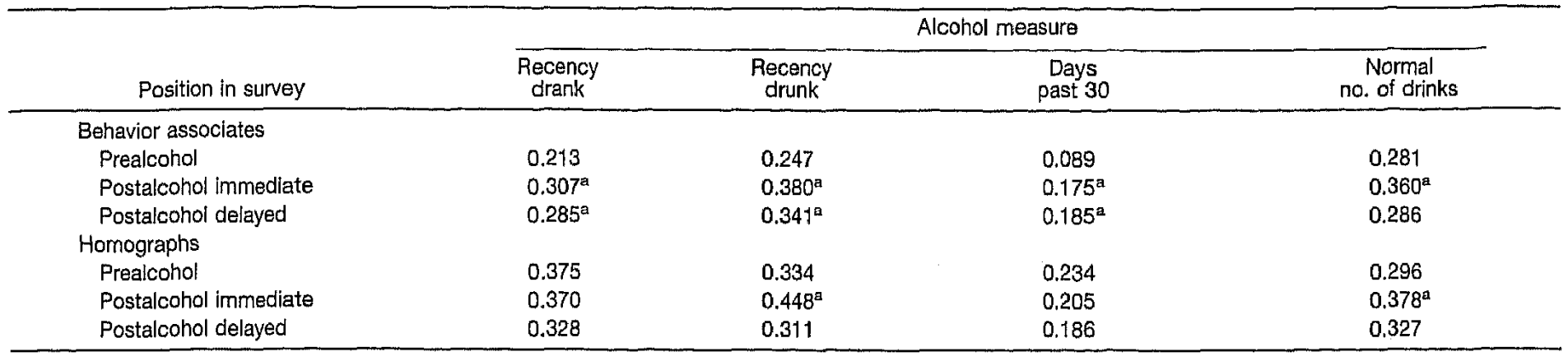

The table shows regression models using behavioral associates and homographs separately controlling for sex and grade for four different dependent measures of drinking behavior. The coefficients are shown and compared as a function of position in survey. Regression coefficients for each individual model all were significant at $p<0.001$.

a Indicates significant $(p<0.05)$ difference from the regression coefficient in the prealcohol condition.

nondrinking adolescents (Krank et al., 2003). The present findings also replicate other demonstrations that retrieval context influences the accessibility of alcohol associations, including those assessed by implicit memory tasks, and support the view that implicit memory tasks measure preexisting alcohol associations that are important to alcohol use decisions. The findings have implications for the assessment of alcohol cognitions in youths. The present findings are novel in showing that the prediction of drinking behavior is modified by methods that improve the retrieval of alcohol associations. Conditions of enhanced retrieval improve the prediction of the level of drinking behavior in young drinkers by implicit memory associations.

\section{DISCUSSION}

\section{Mark S. Goldman}

The papers in this symposium appropriately confine themselves to the domain of cognitive psychology, but full appreciation of this work requires placing it within a larger, transdisciplinary framework. Despite the enormous advances that have been made recently in understanding the genetics and neurophysiology of alcohol use, abuse, and dependence, it is important to understand that these biological processes do not compel drinking. Rather, they alter the matrix of influences that shape behavioral outputs so that the decision to use alcohol becomes either more or less likely. That is, alcohol use requires decision making, albeit decision making that does not necessarily require conscious deliberation (Berridge and Robinson, 1998; Goldman, 2002; Schultz, 2004). How decisions to drink are made is the real topic of this symposium, and the methods described in this symposium open a new window on this process.

This decision making is multidimensional and multilayer; in humans, it represents genetic through sociocultural influences. It is now well understood that genes do not represent a passive blueprint for biological structure and function but are instead ongoing actors in a cascade of mechanisms that determine biobehavioral output. Gene activity is heavily influenced by context. Although extensive review of these processes is well beyond the scope of this discussion, it is essential to understand that context is the common element of all biobehavioral functioning. Gene expression is influenced by other genes (gene context) and by physiological processes in the cell that arise in response to stimulation of the cell by the molecular environment immediately outside the cell (again, a context). This extracellular activity is in turn responsive to neural and hormonal influences that reflect larger response systems within the organism, which is in turn responsive to sensory signals detected at the periphery of the organism, and which, finally, reflect events external to the organism. All of these influences are context, albeit at different levels. The interrelatedness of these levels is such that changes in the external context can influence context all the way down to the genes. That is, what we call learning and memory is essentially the result of the external context triggering a cascade of processes that result ultimately in gene expression. Gene expression then results in actual physical change in neural circuitry that is the mechanism by which experience is recorded. Hence, all of this machinery is part of decision making, and none of it would happen without activity at all levels, including the level of cognition and behavior.

Because behavioral science is fundamentally the study of the interplay between context and the organism, context has always been part of psychological explanation. To appreciate that this is so, it is important to understand that the term stimulus is not a discrete entity. Instead, it refers to a particular event that occurs against the background of a larger stimulus context; it is an arrangement of figure and ground. The boundary between the figure and the ground (context) may not be so clear from the perspective of what constitutes the meaningful signal. Change either, and responding may change. To provide just a few examples of major psychological constructs that involve context, classical conditioning notes the capacity of a stimulus set in a particular context to elicit response output (the conditioned stimulus timed correctly to the presentation of the unconditioned stimulus). The study of stimulus generalization is the investigation of the boundary between the dis- 
tinguishable stimulus and variations of that stimulus that fade into context. Discrimination is the opposite: learning to delimit the intended stimulus from a context that does not signal the occasion for action. Classical stimulusresponse theory treated stimulus and context in a similar manner to that described above in connection with classical conditioning. Operant models refer explicitly to contexts that signal the availability of reinforcement (i.e., discriminative stimuli or SDs; stimulus contexts that signal the unavailability of reinforcement are $S \Delta s$ ). Within the field of psychopharmacology itself, state-dependent learning refers to the greater likelihood that behaviors that are acquired in one drug state (drug context) would be demonstrated in the same drug state.

With the advent of the "cognitive revolution," it became necessary to note the effect of context on response outputs in terms that are consistent with cognitive constructs. The result is the concept of encoding specificity noted in the earlier talks. As with state-dependent learning, encoding specificity recognizes that information that is presented in a certain context (e.g., via a particular set of learning operations, a particular sensory pathway, a particular environment) is better accessed, recalled, etc., in the same (or similar) context, but the idea is the same: context is critical to learning and memory.

With the recent trend toward merging cognitive science with neuroscience, it becomes even clearer why this principle should hold. Organisms have become "designed" through evolution to anticipate upcoming circumstances (Goldman, 2002). They use the full extent of the context in which they find themselves to determine their next behavioral output ("place their bet") on the basis of what they have already experienced in that context. Because extended context is necessarily processed through multiple neural pathways, context must be "assembled" within the nervous system.

The differing methods used to measure the effects of context on cognitive and behavioral output vary, therefore, because they probe different neural pathways. For the present purposes, these pathways may be simply characterized as perceptual, motor, affective, and cognitive. Within each of these domains, aspects are more or less explicit and implicit (Roediger et al., 1999).

Recognition of this complexity should lead us to be excited but cautious about the conclusions that we reach from the initial round of studies presented herein that use varying explicit and implicit cognitive methods. Following are just a few of the questions that must be answered: How does the material that is accessed by language-based cognitive techniques relate to the processes that guide actions and behavioral decisions, such as alcohol use? How do implicit measures relate to explicit measures in this domain? (The results of a few extant studies in the alcohol domain suggest that these tasks are relatively independent, with explicit methods out-predicting implicit methods. More studies are necessary to settle this question.) How do particular implicit measures relate to other implicit measures? (We have too often found that even explicit measures of ostensibly the same construct do not correlate highly with each other; why should implicit measures fare any better? And such studies are difficult to carry out; repeated implicit measurement has a high likelihood of cross contamination.) How well do implicit measures reflect fundamental neuropsychological processes? Can response patterns to cognitive techniques serve as phenotypes that can be related to genetic underpinnings? Do these measures have utility in the clinical domain? Can we control these processes and possibly use them to influence clinical risk?

These and other questions are the next items on our research agenda. The significance of these questions indicates that research on this aspect of decision making about alcohol use remains a promising and exciting venture.

\section{REFERENCES}

Amaro H, Blake SM, Schwartz PM, Flinchbaugh LJ (2001) Developing theory-based substance abuse prevention programs for young adolescent girls. J Early Adolesc 21:256-293.

Arnett JJ (1994) Sensation seeking: a new conceptualization and a new scale. Pers Individ Diff 16:289-296.

Banaji MR, Blair IV, Schwarz N (1996) Implicit memory and survey measurement, in Answering Questions: Methodology for Determining Cognitive and Communicative Processes in Survey Research (Schwarz N, Sudman S eds), pp 347-372. Jossey-Bass, San Francisco.

Berridge KC, Robinson TE (1998) What is the role of dopamine in reward: hedonic impact, reward learning, or incentive salience? Brain Res Brain Res Rev 28:309-369.

Bijl RV, Ravelli A, Van Zessen G (1998) Prevalence of psychiatric disorder in the general population: results of the Netherlands Mental Health Survey and Incidence Study (NEMESIS). Soc Psychiatry Psychiatr Epidemiol 33:587-595.

Birch CD, Stewart SH, Zack M Emotion and motive effects on drugrelated cognition, in Handbook on Implicit Cognition and Addiction. Wiers RW, Stacy AW (eds.), Thousand Oaks, CA, Sage Publishers, in press.

Birch CD, Stewart, SH, Wall AM, McKee SA, Eisnor SJ, Theakston JA (2004) Mood-induced increases in alcohol expectancy strength in internally-motivated drinkers. Psychol Addict Behav 18:231-238.

Blair IV (2002) The malleability of automatic stereotypes and prejudice. Pers Soc Psychol Rev 6:242-261.

Carrigan G, Samoluk SB, Stewart SH (1998) Examination of the short form of the Inventory of Drinking Situations (IDS-42) in a young adult university student sample. Behav Res Ther 36:789-807.

Comeau N, Stcwart SH, Loba P (2001) The relations of trait anxiety, anxiety sensitivity, and sensation seeking to adolescents' motivations for alcohol, cigarette, and marijuana use. Addict Behav 26:803-825.

Conrod PJ, Pihl RO, Stewart SH, Dongier M (2000a) Validation of a system of classifying female substance abusers based on personality and motivational risk factors for substance abuse. Psychol Addict Behav $14: 243-256$

Conrod PJ, Pihl RO, Vassileva J (1998) Differential sensitivity to alcohol reinforcement in groups of men at risk for distinct alcoholism syndromes. Alcohol Clin Exp Res 22:585-597.

Conrod PJ, Stewart SH, Pihl RO, Côté S, Fontaine V, Dongier M (2000b) Efficacy of brief coping skills interventions that match different personality profiles of female substance abusers. Psychol Addict Behav 14:231242. 
Cooper ML (1994) Motivations for alcohol use among adolescents: development and validation of a four-factor model. Psychol Assess 6:117128.

Cooper ML, Frone MR, Russell M, Mudar P (1995) Drinking to regulate positive and negative emotions: a motivational model of alcohol use. J Pers Soc Psychol 69:990-1005.

Cooper ML (1994) Motivations for alcohol use among adolescents: Development and validation of a four-factor model. Psychol Assess 6:117128.

Crombag HS, Robinson TE (2004) Drugs, environment, brain and behaviour. Curr Direct Psychol Sci 13:107-111.

Cuijpers P, Jonkers R, De Weerdt I, De Jong A (2002) The effects of drug abuse prevention at school: the "Healthy School and Drugs" project. Addiction 97:67-73.

Darkes J, Goldman MS (1993) Expectancy challenge and drinking reduction: experimental evidence for a mediational process. J Consult Chin Psychol 61:344-353.

De Houwer J (2003) The extrinsic affective Simon task. Exp Psychol 50:77-85.

De Houwer J, Crombez G, Koster EHW, De Beul N (2004) Implicit alcohol-related cognitions in a clinical sample of heavy drinkers. $J$ Behav Ther Exp Psychiatry 35:255-286.

Dimeff LA, Bear JS, Kivlahan DR, Marlatt GA (1999) BASICS: Brief Alcohol Screening and Intervention for College Students: $A$ Harm Reduction Approach. The Guilford Press, New York.

Fazio RH (1990) A practical guide to the use of response latency in social psychological research, in Research Methods in Personality and Social Psychology. Review of Personality and Social Psychology (Hendrick C, Clark MS eds), vol 11, pp 74-97. Sage Publications, Newbury Park, CA.

Fazio RH, Olson MA (2003) Implicit measures in social cognition research; their meaning and use. Annu Rev Psychol 54:297-327.

Fromme K, Marlatt GA, Baer JS, Kivlahan DR (1994) The alcohol skills training program: group intervention for young adult drinkers. J Subst Abuse Treat 11:143-154.

Fromme K, Stroot E, Kaplan D (1993) Comprehensive effects of alcohol: development and psychometric assessment of a new expectancy questionnaire. Psychol Assess 5:19-26.

Glautier S, Spencer K (1999) Activation of alcohol-related associative networks by recent alcohol consumption and alcohol-related cues. Addiction 94:1033-1041.

Glicksman L, Demers A, Adlaf EM, Newton-Taylor B, Schmidt K (2000) Canadian Campus Suney. Centre for Addiction and Mental Health, Toronto.

Goldman MS (1999) Risk for substance abuse: memory as a common etiological pathway. Psychol Sci 10:196-198.

Goldman MS (2002) Expectancy and risk for alcoholism: the unfortunate exploitation of a fundamental characteristic of neurobehavioral adaptation. Alcohol Clin Exp Res 26:737-746.

Goldman MS, Del Boca FK, Darkes J (1999) Alcohol expectancy theory: the application of cognitive neuroscience, in Psychological Theories of Drinking and Alcoholism (Leonard KE, Blane HT eds), 2nd ed, pp 203-246. The Guilford Press, New York.

Grant BF, Dawson DA (1997) Age at onset of alcohol use and its association with DSM-IV alcohol abuse and dependence: results from the national longitudinal alcohol epidemiologic survey. I Subst Abuse 9:103-110.

Greeley J, Oei T (1999) Alcohol and tension reduction, in Psychological Theories of Drinking and Alcoholism (Leonard KE, Blane HT eds), 2nd ed., pp 14-53. New York; The Guilford Press.

Havermans RC, Vancleef L, Bylois E, Wiers RW, Jansen A (2005) Context dependent access to alcohol-related concepts stored in memory. Alcohol Res, in press.

Hawkins JD, Graham JW, Maguin E, Abbott R, Hill KG, Catalano RF (1997) Exploring the effects of age on alcohol use initiation and psychosocial risk factors on subsequent alcohol misuse. I Stud Aicohol $58: 280-290$.
Johnson TR, Krank MD, Wall A-M, Lai D, Wekerle C (2004) Alcohol use and cognitions predict future social problems in adolescents. Alcohol Clin Exp Res 28:105A.

Kaminer Y (1999) Addictive disorders in adolescents. Addict Disord 22:275-287.

Kandel DB, Davies M, Karus D, Yamaguchi K (1986) The consequences in young adulthood of adolescent drug involvement. Arch Gen Psychiatry $43: 746-754$.

Krank MD (2002) An episodic memory model of alcohol cognitions. Alcohol Clin Exp Res 26:135A.

Krank MD, Wall AM, Lai D, Wekerle C, Johnson T (2003) Implicit and explicit cognitions predict alcohol use, abuse and intentions in young adolescents. Alcohol Clin Exp Res 27:160A.

Larimer ME, Cronce JM (2002) Identification, prevention and treatment: a review of individual-focused strategies to reduce problematic alcohol consumption by college students. J Stud Alcohol (Suppl) $14: 148-163$.

Levine B, Goldman MS (1989) Situational variations in expectancies. Paper presented at the 97th Annual Convention of the American Psychological Association, August 1989, New Orleans.

MacLatchy-Gaudet HA, Stewart SH (2001) Context-specific positive alcohol outcome expectancies of university women. Addict Behav 26:3149.

Marlatt GA, Demming B, Reid JB (1973) Loss of control drinking in alcoholics: an experimental analoguc. J Abnorm Psychol 81:233-241.

Miller WR, Rollnick S (1991) Motivational Interviewing: Preparing People to Change Addictive Behaviors. Guilford Press, New York.

Monti PM, Barnett NP, O'Leary TA, Colby SM (2001) Motivational enhancement for alcohol-involved adolescents, in Adolescents, Alcohol, and Substance Abuse: Reaching Teens Through Brief Interventions (Monti PM, Colby SM eds), pp 145-182. Guilford Press, New York.

Newcomb MD, Bentler PM (1989) Substance use and abuse among children and teenagers. Am Psychol 44:242-248.

Palfai TP, Monti PM, Ostafin B (2000) Effects of nicotine deprivation on alcohol-related information processing and drinking behavior. $\mathrm{J}$ Abnorm Psychol 109:96-105.

Palfai TP, Ostafin BD (2003) Alcohol-related motivational tendencies in hazardous drinkers: assessing implicit response tendencies using the modified IAT. Behav Res Ther 41:1149-1162.

Pihl RO, Peterson JB (1995) Alcoholism: the role of different motivntional systems. J Psychiatry Neurosci 20:372-396.

Rescorla RA (1988) Pavlovian conditioning: it's not what you think it is. Am Psychol 43:151-160.

Robinson TE, Berridge KC (2003) Addiction. Annu Rev Psychol 54:2553.

Roediger HL, Buckner RL, McDermott KB (1999) Components of processing, in Memory: Systems, Process, or Function (Foster JK, Jelicic M eds), pp 31-65. Oxford University Press, New York.

Roehrich L, Goldman MS (1995) Implicit priming of alcohol expectancy memory processes and subsequent drinking behavior. Exp Clin Psychopharmacol 3:402-410.

Scheier LM, Botvin GJ (1998) Relations of social skills, personal competence, and adolescent alcohol use: a developmental exploratory study. $\mathbf{J}$ Early Adolesc 18:77-114.

Schultz W (2004) Neural coding of basic reward terms of animal learning theory, game theory, microeconomics and behavioural ecology. Curr Opin Neurobiol 14:139-147.

Schwarz N (1999) Self-reports. How questions shape the answers. An Psychol 54:93-105.

Segal ZV, Gemar M, Truchon C, Guirguis M, Horowitz LM (1995) A priming methodology for studying self-representation in major depressive disorder. J Abnorm Psychol 104:205-213.

Silverman WK, Fleisig W, Rabian B, Peterson RA (1991) Childhood Anxiety Sensitivity Index. J Clin Child Psychol 20:162-168.

Single E, Wortley S (1993) Drinking in various settings as it relates to demographic variables and level of consumption: findings from a National Survey in Canada. J Stud Alcohol 54:590-599. 
Singleton EG, Tiffany ST, Henningfield JE (1994) The multidimensional aspects of craving for alcohol. Unpublished research, Intramural Research Program, National Institute on Drug Abuse, National Institutes of Health, Baltimore, MD.

Stacy AW (1997) Memory activation and expectancy as prospective predictors of alcohol and marihuana use. J Abnorm Psychol 106:6173.

Stacy AW, Ames SL, Sussman S, Dent CW (1996) Implicit cognition in adolescent drug use. Psychol Addict Behav 10:190-203.

Stein KD, Goldman MS, Del Boca FK (2000) The influence of alcohol expectancy priming and mood manipulation on subsequent alcohol consumption. J Abnorm Psycho] 109:106-115.

Stewart SH, Devine H (2000) Relations between personality and drinking motives in young adults. Pers Individ Diff 29:495-511.

Stewart SH, Karp J, Pihl RO, Peterson RA (1997) Anxiety sensitivity and self-reported reasons for drug use. J Subst Abuse 9:223-240.

Stewart SH, Loughlin HL, Rhyno E (2001) An examination of the mediating roles of internal drinking motives in explaining personality domain-drinking behavior relations in young adults. Pers Individ Diff 30:271-286.

Stewart SH, Zeitlin SB (1995) Anxiety sensitivity and alcohol use motives. J Anxiety Disord 9:229-240.

Stewart SH, Hall E, Wilkie H, Birch C (2002) Affective priming of alcohol schema in coping and enhancement motivated drinkers. Cogn Behav Ther 31:68-80.

Strack F, Deutsch R (2004) Reflective and impulsive determinants of social behavior. Pers Soc Psychol Rev 3:220-247.

Theakston JA, Stewart SH, Dawson M, Knowlden-Loewen S, Lehman DR (2004) Big-five personality domains predict drinking motives. Pers Individ Diff 37:971-984.

Tulving E (1983) Elements of Episodic Memory, Oxford University Press, New York.

Wagner EF, Brown SA, Monti PM, Myers MG, Waldron HB (1999) Innovations in adolescent substance abuse intervention. Alcohol Clin Exp Res 23:236-249.

Wall A-M, McKee SA, Hinson RE (2000) Assessing variation in alcohol outcome expectancies across environmental contexts: an exami- nation of the situational-specificity hypothesis. Psychol Addict Behav 14:367-375.

Wall A-M, McKee SA, Hinson RE, Goldstein A (2001) Examining alcohol outcome expectancies in laboratory and naturalistic bar settings: a within-subject analysis. Psychol Addict Behav 15:219-226.

White NM (1996) Addictive drugs as reinforcers: multiple partial actions on memory systems. Addiction 91:921-949.

White HR, Labouvie EW (1989) Towards the assessment of adolescent problem drinking. J Stud Alcohol 50:30-37.

Wicrs RW, De Jong PJ, Havermans R, Jelicic M (2004) How to change implicit drug use-related cognitions in prevention: a transdisciplinary integration of findings from experimental psychopathology, social cognition, memory and experimental learning theory. Subst Use Misuse 39:1625-1684.

Wiers RW, Ganushchack L, Van de Ende N, Smulders FTY, De Jong PJ (2003a) Comparing Implicit Alcohol Associations Across Different RTMeasures: The Implicit Association Test (IAT) Versus Varieties of the Extrinsic Affective Simon Task (EAST). Paper presented at the 15th Annual Convention of the American Psychological Society; Atlanta, GA; May 29-June 1.

Wiers RW, Hoogeveen KJ, Sergeant JA, Gunning WB (1997) High and low dose expectancies and the differential associations with drinking in male and female adolescents and young adults. Addiction 92:871-888.

Wiers RW, Kummeling RHC (2004) An experimental test of an alcohol expectancy challenge in mixed gender groups of heavy young drinkers. Addict Behav 29:215-220.

Wiers RW, Stacy AW, Ames SL, Noll, Jane A, Sayette MA, Zack M, Krank M (2002a) Implicit and explicit alcohol-related cognitions. Alcohol Clin Exp Res 26:129-137.

Wiers RW, van Woerden N, Smulders FTY, De Jong PJ (2002b) Implicit and explicit alcohol-related cognitions in heavy and light drinkers. $J$ Abnorm Psychol 111:648-658.

Wiers RW, Wood MD, Darkes J, Corbin WR, Jones BT, Sher KJ (2003b) Changing expectancies: cognitive mechanisms and context effects. Alcohal Clin Exp Res 27:186-197.

Wigmore SW, Hinson RE (1991) The influence of setting on consumption in the balanced placebo design. Br $\mathbf{J}$ Addict 86:205-215. 